\title{
Pre-operative high-dose-rate brachytherapy in early-stage cervical cancer: long-term single-center results
}

\author{
Sylwia Kellas-Ślęczka, MD, PhD', Piotr Wojcieszek, MD, PhD', Marta Szlag, PhD², Magdalena Stankiewicz, MD, PhD!, \\ Agnieszka Cholewka, MSC2, Maciej Ślęczka, PhD³, Agnieszka Badora-Rybicka, MD, PhD4, Piotr Lelek, MD!, \\ Agnieszka Pruefer, MSC2 , Tomasz Krzysztofiak, MD', Zofia Kołosza, MSC ${ }^{5}$, Marek Fijałkowski, MD' \\ 'Brachytherapy Department, Maria Skłodowska-Curie National Research Institute of Oncology, Gliwice Branch, Poland, ${ }^{2}$ Radiotherapy \\ Planning Department, Maria Skłodowska-Curie National Research Institute of Oncology, Gliwice Branch, Poland, ${ }^{3}$ Institute of Mathematics, \\ University of Silesia in Katowice, Katowice, Poland, ${ }^{B}$ Breast Cancer Unit, Maria Skłodowska-Curie National Research Institute of Oncology. \\ Gliwice Branch, Poland, ${ }^{5}$ Department of Biostatistics and Bioinformatics, Maria Skłodowska-Curie National Research Institute of Oncology. \\ Gliwice Branch, Poland
}

\begin{abstract}
Purpose: The aim of the study was to report the outcomes of pre-operative high-dose-rate brachytherapy (pHDRBT), followed by hysterectomy in patients with early cervical cancer.

Material and methods: From January, 1998 to December, 2003, 113 women with IB1, IB2, and IIA1 cervical cancer (according to International Federation of Gynecology and Obstetrics [FIGO] 2018) were treated with pHDR-BT, and 6 to 8 weeks later followed by radical hysterectomy. Patients found to have positive lymph nodes, residual cervical cancer, involved parametria, or lymphovascular space invasion (LVSI) received post-operative adjuvant therapy.

Results: Post-operatively, $81.4 \%$ of patients had a complete response to pHDR-BT in the cervix, and $18.6 \%$ had residual cervical cancer. Failures occurred in 11/113 (9.7\%) patients (all were stage IIA1), with pelvic recurrences in $5 / 113(4.4 \%)$ and distant metastasis (DM) in 6/113 (5.3\%). The 5- and 10-year disease-free survival (DFS) rates were $100 \%$ for IB1 and IB2, and $86.4 \%$ and $81.3 \%$ for IIA1, respectively. Lymph node involvement and/or residual cervical cancer correlated with worse DFS. Two vesicovaginal fistulas were observed (one in a patient treated only with pHDRBT and one in a woman, who underwent adjuvant external-beam radiotherapy [EBRT]). Two rectovaginal fistulas and one case of proctitis were observed in patients treated with adjuvant EBRT.

Conclusions: pHDR-BT in early cervical cancer is well-tolerated and effective in sterilizing tumor cells in the cervix. The growing number of publications in this area may help define an optimal therapeutic scheme, but randomized trials are required to determine the best candidates for this treatment modality.

In our opinion, cervical cancer patients with FIGO stage IIA1 are not good candidates for pHDR-BT, and could be given this treatment only after rigorous selection, including assessment with state-of-the-art imaging, due to higher probability of treatment failure.

Key words: pre-operative, brachytherapy, HDR, cervical cancer.

\section{Purpose}

Cervical cancer is the fourth most common cancer among women globally [1, 2]. In 2018, an estimated number of 569,847 new cases of cervical cancer were diagnosed worldwide, and 311,365 deaths occurred [2].

Various treatment strategies with comparable outcomes are available, but the most commonly used is radical hysterectomy with lymphadenectomy, followed by adjuvant therapy in case of high-risk factors for failure
[2-6]. Brachytherapy (BT) is crucial in the treatment of all cervical cancer stages [3, 6-8]. It delivers a high-dose of radiation directly to the tumor while sparing healthy tissue. It is also associated with high local control and acceptable toxicity [7-13]. In cases of operable disease, BT is usually administered post-operatively $[6,7,13]$, but in selected patients, it may be performed before surgery [3-7, 14-16].

In the pre-operative setting, BT has been reported as an effective method for sterilizing tumor cells in the

Address for correspondence: Sylwia Kellas-Ślęczka, Brachytherapy Department, Maria Skłodowska-Curie Received: 27.06.2021 National Research Institute of Oncology, Gliwice Branch, Wybrzeże Armii Krajowej 15, 44-102 Gliwice, 
cervix $[7,14,15,17]$. Moreover, it is considered an approach that may decrease the extent of surgery and need for adjuvant pelvic EBRT [5, 11, 16, 17]. In France, pre-operative BT (pBT) is one of the treatment options available for selected early, operable cervical cancer patients $[3,10,12,17]$. However, there is no strong evidence from prospective studies to justify this option. The role of pre-operative low-dose-rate brachytherapy (pLDRBT) and pre-operative pulsed-dose-rate brachytherapy (pPDR-BT) is well-documented [3, 4, 9, 10, 18-23], but there are few reports on the use of pre-operative highdose-rate brachytherapy (pHDR-BT) [12, 15, 24, 25]. In the European Society of Gynecological Oncology (ESGO) recommendations, pBT followed by surgery (type A) is suggested as an alternative option for high-risk and intermediate-risk IB1/IIA1 (International Federation of Gynecology and Obstetrics [FIGO] 2009) patients, but only performed by experienced specialists [6]. In our center, pHDR-BT has been used as a treatment strategy in early, operable cervical cancer for 38 years [24]. This study aimed to retrospectively analyze the long-term efficacy and toxicity of pHDR-BT in IB1, IB2, and IIA1 (FIGO 2018 [26]) cervical cancer patients.

Table 1. Patients and tumor characteristics

\begin{tabular}{lcc}
\hline Parameter & $n$ & $\%$ \\
\hline Age (years), median (range) & $51(28-64)$ & \\
\hline FIGO stage & & \\
\hline IB1 & 12 & 10.6 \\
\hline IB2 & 42 & 37.2 \\
\hline IIA1 & 59 & 52.2 \\
\hline Histopathology & & \\
\hline Squamous cell carcinoma & 110 & 97.3 \\
\hline Adenocarcinoma & 3 & 2.7 \\
\hline Differentiation grade & & \\
\hline G1 & 10 & 8.9 \\
\hline G2 & 28 & 24.7 \\
\hline G3 & 5 & 4.4 \\
\hline Not found & 70 & 62.0 \\
\hline Cervical diameter (cm) & 106 & \\
\hline$\leq 2.0$ & 12 & 10.6 \\
\hline $2.1-3.5$ & 90 & 79.6 \\
\hline $3.6-3.9$ & 11 & 9.8 \\
\hline Lymphovascular space invasion & & \\
\hline Present & & \\
\hline Absent & & \\
\hline Lymph node removed, median (range) & 12.8 \\
\hline Ovarian transposition & & \\
\hline Yes & & \\
\hline No & & \\
\hline
\end{tabular}

\section{Material and methods}

\section{Patients' characteristics}

Between January, 1998 and December, 2003, 151 patients with stage IB1, IB2, and IIA1 (stage updated to FIGO 2018) cervical cancer were treated with pHDR-BT in our department. We enrolled 113 patients with a tumor less than $4.0 \mathrm{~cm}$ in diameter treated with a ring applicator. Patients who had had a primary cone biopsy were excluded from the study to ensure that the tumor response observed in post-operative histology was related only to pBT. Median primary tumor size was $3.0 \mathrm{~cm}$ (range, 2.0-3.9 cm). Patient and tumor characteristics are shown in Table 1. Human papillomavirus (HPV) status was not evaluated.

Before brachytherapy, all women underwent staging workup, i.e., general clinical examination, transabdominal and transvaginal ultrasound, chest $X$-ray, urography, and fluoroscopy. In the period covered by the study, computed tomography (CT) and/or magnetic resonance imaging (MRI) were performed only in selected cases, because of limited access to imaging equipment. All patients provided written informed consent to the proposed treatment.

\section{Brachytherapy procedure}

Patients were hospitalized during pBT. All had a Foley catheter filled with $7 \mathrm{~cm}^{3}$ of contrast inserted before each fraction. All patients were treated with a ring applicator (Nucletron, Elekta AB, Stockholm, Sweden) inserted under general anesthesia after cervical canal dilatation. Ring applicator had a diameter of either $26 \mathrm{~mm}$ or $30 \mathrm{~mm}$, and intrauterine tubes were either $40 \mathrm{~mm}$ or $60 \mathrm{~mm}$ in length. The size of applicator and the length of intrauterine source was chosen individually for each patient, based on anatomical conditions. After each fraction, the applicator and Foley catheter were removed.

\section{Brachytherapy planning and dosimetry}

Pre-operative brachytherapy was based on 2D treatment planning. After applicator insertion, radiographs were performed with dummy sources. Treatment plans were calculated with PLATO BPS version 14.2.6 (Nucletron, The Netherlands) and treatment was performed with a remote high-dose-rate $\operatorname{Ir}^{192}$ afterloading source (MicroSelectron, Nucletron, Elekta AB, Stockholm, Sweden). Patients were treated twice a week in 6 fractions (with three or four days between each fraction), with a fractionation dose of 5 Gy prescribed to point A (total dose of 30 Gy to point A). Biologically effective dose (BED) was calculated using formula: $\mathrm{BED}=\mathrm{nD}(1+\mathrm{D} \div(\alpha / \beta))$.

$\mathrm{BED}$ and equivalent dose in $2 \mathrm{~Gy}$ fractions $\left(\mathrm{EQD}_{2}\right)$ for $\alpha / \beta=10$ at point A were 45 Gy and 37.5 Gy, respectively. Doses delivered to the bladder and rectal reference points were defined according to the International Commission on Radiation Units and Measurements (ICRU 38). Median dose at the bladder and rectal points was 18.6 Gy (range, 5.7-32.4 Gy) and 16.8 Gy (range, 10.8-29.4 Gy), respectively. Median $\mathrm{BED}$ and $\mathrm{EQD}_{2}$ at the bladder point 
was 37.8 Gy (for $\alpha / \beta=3$ ) and 22.7 Gy, respectively, and at the rectal point was $32.5 \mathrm{~Gy}$ and $19.5 \mathrm{~Gy}$, respectively.

\section{Surgery}

Six to eight weeks after pHDR-BT, all patients underwent laparotomy, all in a single gynecology department. Piver II type radical hysterectomy was performed with removal of median half of the cardinal and uterosacral ligaments, ligating the uterine artery at the ureter. Pelvic lymphadenectomy was done during hysterectomy, and included external, internal, and common iliac lymph nodes with frozen section analysis. Para-aortic lymph node dissection was performed if enlarged nodes were present. For patients aged under 40 , an ovarian transposition was done (Table 1 ).

\section{Adjuvant therapy}

Patients were qualified for post-operative adjuvant EBRT with concurrent chemotherapy when one or more of the following risk factors for failure was present: lymphovascular space invasion (LVSI), residual cervical cancer after $\mathrm{pBT}$, involved lymph nodes, parametria, or margins. Adjuvant treatment was not given to patients with no tumor cells in post-operative specimens. Whole pelvic EBRT was administered with $\gamma \mathrm{Co}-60$ or 6-20 MV photons, using conventional planning (i.e., 2- or 4-field box technique). Total dose was $45 \mathrm{~Gy}$, with a daily dose per fraction of 1.8 Gy. Cisplatin-based chemotherapy was administered, with a dose of $30-40 \mathrm{mg} / \mathrm{m}^{2}$ in 5-7 cycles given weekly.

\section{Follow-up}

Patients were followed up at 3-6 month intervals for the first 5 years and then annually. The follow-up time was calculated from the start of pHDR-BT. Failures were classified as pelvic recurrences or distant metastases.

Analysis endpoints were overall survival (OS), local control (LC), disease-free survival (DFS), and cause-specific survival (CSS). These were defined as the time between surgery and the date of the incident (death - OS; relapse, second cancer, or death - DFS; death from the disease - CSS) or last follow-up. LC was specified as the arrest of cancer growth at the site of origin. Acute ( $\leq 6$ months from the start of pHDR-BT, combined with complications following surgery) and late (> 6 months) gastrointestinal (GI) and genitourinary (GU) toxicity were evaluated using the Common Terminology Criteria for Adverse Events (CTCAE), version 5.0 [27].

\section{Statistical analysis}

Statistica 13.1 (StatSoft) software was used for statistical analysis. Five- and 10-year OS, LC, DFS, and CSS were calculated with Kaplan-Meier method. A log-rank test was used to compare sub-groups. Independent prognostic factors were investigated with Cox proportional hazards model. Multivariate analysis results were described as hazard ratios (HR) and 95\% confidence intervals (CI). A $p$-value of $<0.05$ was defined as statistically significant.

\section{Results}

The median follow-up was 210 months (range, 17268 months). Twelve (10.6\%) women were staged as IB1, $42(37.2 \%)$ as IB2, and $59(52.2 \%)$ as IIA1. The median pHDR-BT treatment time was 21 days (range, 17-29 days). All the patients underwent surgery six to eight weeks after $\mathrm{pHDR}-\mathrm{BT}$.

\section{Post-operative histopathology}

In post-operative histopathology, 92/113 women $(81.4 \%)$ had a complete response to pHDR-BT in the cervix, while residual cervical cancer was present in 21/113 (18.6\%) patients. Macroscopic residual disease was found in $13 / 21$ cases $(61.9 \%)$ and microscopic disease in $8 / 21$ $(38.1 \%)$. Four patients had parametrial tumor spread (3.5\%). There was no case of margin involvement. Lymph node involvement was observed in $17 / 113(15 \%)$ patients, including $4 / 42$ (9.5\%) with IB2 and 13/59 (22\%) with IIA1 (Table 2). The median tumor size in patients with lymph node involvement was $3.3 \mathrm{~cm}$ (range, $2.5-3.9 \mathrm{~cm}$ ).

\section{Adjuvant therapy}

Thirty-two patients $(28.3 \%)$ had risk factors for failure post-operatively, but only $21 / 31$ received adjuvant treatment: $12 / 32(37.5 \%)$ had EBRT with concurrent chemotherapy, 5/32 (15.6\%) had EBRT alone, and 4/32 $(12.5 \%)$ had chemotherapy alone. EBRT alone was given only if there was a residual tumor of less than $1 \mathrm{~mm}$ in the cervix. The four cases, in which chemotherapy alone was used, were because one patient had undergone pelvic radiotherapy in the past, one had an extensive burn scar from childhood, and two did not consent to EBRT. The standard EBRT dose was 45 Gy, but in three patients, the dose was 52 Gy (with a daily dose per fraction of 2 $\mathrm{Gy})$, due to poor response to $\mathrm{pBT}$. In patients with lymph node extracapsular spread (one patient) or parametrial invasion (four patients), a 10 Gy boost was given.

Eleven patients $(34.3 \%)$ did not undergo the planned treatment due to an extended time ( $>3$ months) between surgery and the visit to our center, although they were followed-up. Three cases of failure occurred in these patients.

Table 2. Response to brachytherapy $(n=113)$

\begin{tabular}{lcc} 
Response & $\begin{array}{c}\text { Number of } \\
\text { patients }\end{array}$ & $\%$ \\
\hline $\begin{array}{l}\text { Complete response to pHDR-BT } \\
\begin{array}{l}\text { No residual cervical cancer } \\
\text { and negative lymph nodes }\end{array}\end{array}$ & 92 & 81.4 \\
\hline $\begin{array}{l}\text { No residual cervical cancer } \\
\text { and involved lymph nodes }\end{array}$ & 10 & 72.6 \\
\hline $\begin{array}{l}\text { Incomplete response to pHDR-BT } \\
\text { Residual cervical cancer } \\
\text { and negative lymph nodes }\end{array}$ & 21 & 8.8 \\
\hline $\begin{array}{l}\text { Residual cervical cancer } \\
\text { and involved lymph nodes }\end{array}$ & 14 & 18.6 \\
\hline $\begin{array}{l}\text { Involved lymph nodes } \\
\text { Parametrial invasion }\end{array}$ & 7 & 6.2 \\
\hline
\end{tabular}


Table 3. Pattern of failure $(n=113)$

\begin{tabular}{|c|c|c|c|c|c|c|c|}
\hline \multirow[t]{3}{*}{ Failures } & \multirow{2}{*}{\multicolumn{2}{|c|}{ FIGO stage }} & \multicolumn{4}{|c|}{ Post-operative histology in failures } & \multirow{3}{*}{$\begin{array}{c}\text { Total number } \\
(\%)\end{array}$} \\
\hline & & & \multicolumn{2}{|c|}{ Lymph node status } & \multicolumn{2}{|c|}{ Residual cervical cancer } & \\
\hline & IB1, IB2 & IIA1 & Negative & Involved & Absent & Present & \\
\hline $\begin{array}{l}\text { Pelvic } \\
\text { recurrences }\end{array}$ & - & 5 & 5 & - & 1 & 4 & $5(4.4)$ \\
\hline $\begin{array}{l}\text { Distant } \\
\text { metastases }\end{array}$ & - & 6 & 2 & 4 & 4 & 2 & $6(5.3)$ \\
\hline
\end{tabular}

\section{Failures}

Failures occurred in 11/113 (9.7\%) patients, including pelvic recurrences in 5/113 (4.4\%) (two vaginal and three pelvic nodal failures) and distant metastases in $6 / 113$ (5.3\%) (one liver, one pulmonary, and four nodal metastases). Eight of the 11 failures occurred in patients with residual cervical cancer and/or with involved lymph nodes. All patients with failure were FIGO stage IIA1 (Table 3). The median time to pelvic recurrence and distant metastasis was 33 months (range, 11-61 months) and 56 months (range, 4-100 months), respectively.

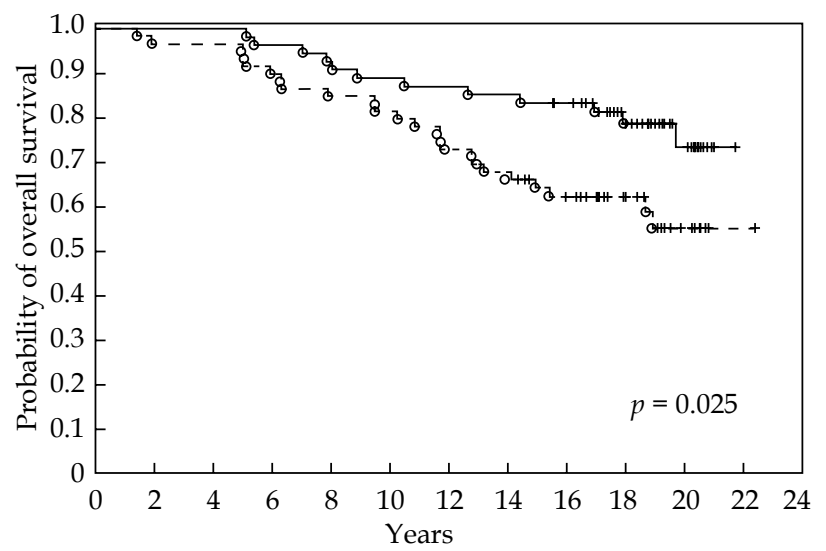

Number of patients at risk

- IB1 + IB2

$\begin{array}{rrrrrrrrrrrr}54 & 54 & 54 & 52 & 50 & 48 & 47 & 46 & 43 & 30 & 14 & \\ - \text { IIA1 } & & & & & & & & & & & \\ 59 & 57 & 57 & 53 & 50 & 48 & 43 & 39 & 31 & 20 & 9 & 1\end{array}$

Fig. 1. Overall survival (OS) according to FIGO stage groups

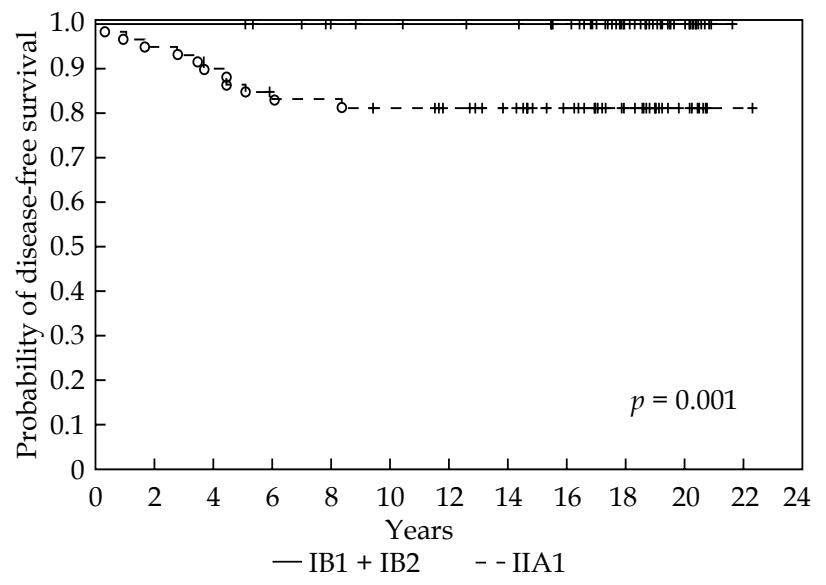

Fig. 2. Disease-free survival (DFS) according to FIGO stage groups

\section{Outcomes}

The 5- and 10-year OS rates for the whole group were $97.3 \%$ and $85.0 \%$, respectively. There was a significant difference in OS between IB1 and IB2, and IIA1 sub-groups $(p=0.025)$. The 5 - and 10-year OS rates for stage IB1 and IB2 were $100.0 \%$ and $88.9 \%$, and for stage IIA1, $94.9 \%$ and $81.4 \%$, respectively (Figure 1). The 5- and 10-year DFS rates for the whole group were $92.9 \%$ and $90.2 \%$, respectively. The 5- and 10-year DFS rates were $100.0 \%$ for stage IB1 and IB2. Stage IIA1 patients had significantly lower rates of 5- and 10-year DFS showing $86.4 \%$ and $81.3 \%$, respectively $(p=0.001)$ (Figure 2$)$. The 5- and 10-year CSS rates for the whole group were $97.3 \%$ and $91.9 \%$, respectively. Five- and 10-year CSS was $100.0 \%$ for IB1 and IB2, and $94.9 \%$ and $84.6 \%$ for IIA1, respectively. The difference in CSS between the sub-groups was statistically significant $(p=0.001)$ (Figure 3$)$. Moreover, statistically significant differences for DFS and CSS were identified and were dependent on post-operative histopathology $(p=0.005$ and $p=0.006$, respectively) (Figures 4 and 5). In Cox regression, post-operative histological findings, such as lymph node involvement and/ or residual cervical cancer, correlated with worse DFS (Table 4).

\section{Acute and late toxicities}

In 23 women (20.3\%), G1 urinary urgency occurred, which resolved spontaneously before surgery within 4-5 weeks. Lymphatic edema in the lower limbs was observed in 9 cases (8\%), which usually occurred 3-6 weeks after surgery. Two women developed G2 lymphatic pseudocysts, two others had G3 wound dehiscence, one

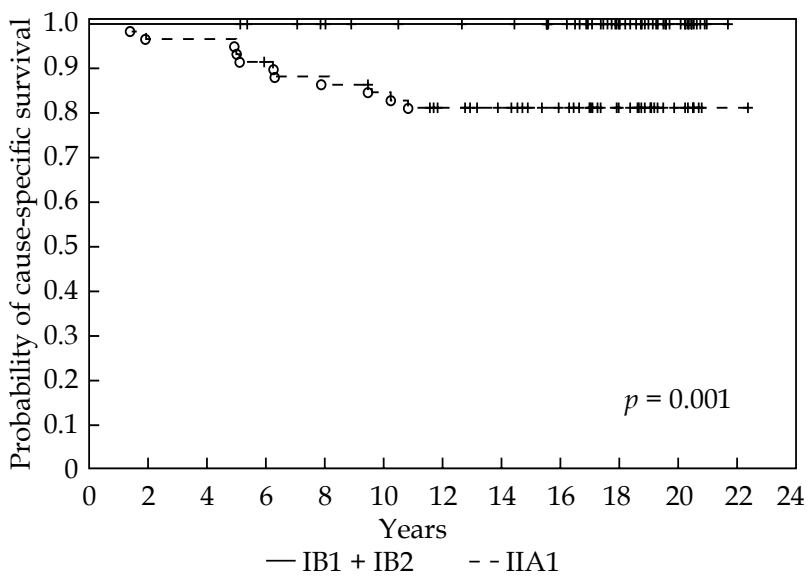

Fig. 3. Cause-specific survival (CSS) according to FIGO stage groups 
experienced G3 post-operative bleeding (four hours after hysterectomy), one suffered from deep vein thrombosis (G2), and one developed a G3 ileus.

Severe late G3 GU toxicities were observed in two patients. A vesicovaginal fistula was diagnosed in one patient treated only with pHDR-BT, and in one treated with adjuvant EBRT with concurrent chemotherapy. Severe late G3 GI toxicities were observed only in patients treated with adjuvant EBRT and concurrent chemotherapy. There were two cases of rectovaginal fistula and one case of proctitis. In addition, three patients treated with adjuvant EBRT complained of G2 dyspareunia without stenosis, and two other women suffered from proximal vaginal stenosis.

\section{Discussion}

Pre-operative brachytherapy is one of several therapeutic options in early, operable cervical cancer, and its' contribution to improving clinical outcome has been demonstrated in many studies (Table 5). The reported DFS ranges from $63.0 \%$ (stage IIA) to $100.0 \%$ [3, 4, 9, 10, $12,15-19,21-25]$, but most studies were based on pLDR$\mathrm{BT}$ and pPDR-BT. In the past, some authors have been uncertain of the potential effect of high doses used in high-dose-rate BT (HDR-BT) on late toxicity. However, many studies have compared low-dose-rate BT (LDR-BT) with HDR-BT in the management of cervical cancer, and have demonstrated comparable LC, survival, and morbidity [28].

In our department, pHDR-BT has been performed for almost 40 years, which means our group of patients has one of the longest periods of follow-up described for this technique. In addition, all of our patients received brachytherapy in a single brachytherapy department and underwent surgery in a single gynecology department. For many years, we used pHDR-BT to treat IB1 and IB2 patients, but we also treated stage IIA1 cervical cancer, as this was common practice at that time (Table 5). In our group of patients, pathologic complete response ( $\mathrm{pCR}$ ) to $\mathrm{pHDR}-\mathrm{BT}$ in the cervix was $81.4 \%$. This is similar to data from other studies, which show results ranging from $26.0 \%$ to $88.0 \%[3,10,12,17,18,21,22,25]$. One study using pLDR-BT (Cs-137) showed a pCR of $71.3 \%$, with FIGO IIA patients achieving pCR less frequently [21]. Bataille et al. observed that $76 \%$ of patients achieved pCR after pPDR-BT, but their study is only available as an abstract [14]. In another study with pPDR-BT, pCR was achieved in $70.1 \%$ of cases [9], and in a prospective trial comparing two-dimensional with three-dimensional pPDR-BT, pCR was observed in $55.0 \%$ and $63.0 \%$ of patients, respectively [13]. Hannoun-Levi et al. used modern pHDR-BT (based on Groupe Européen de Curiethérapie and European

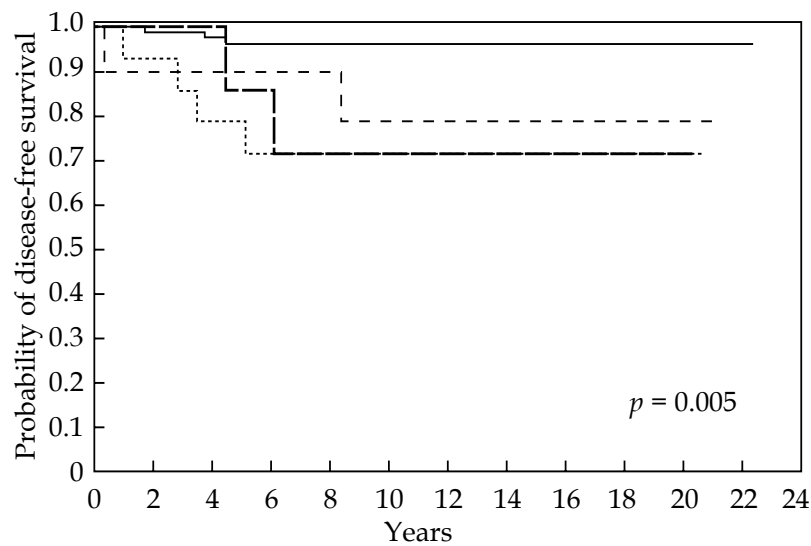

Number of patients at risk

$\begin{array}{lllllllllllll}\text { A } & 82 & 81 & 80 & 77 & 75 & 72 & 69 & 65 & 57 & 37 & 16 & 1\end{array}$

$\begin{array}{llllllllllll}\text { B } & 14 & 13 & 11 & 10 & 10 & 10 & 9 & 8 & 8 & 6 & 2\end{array}$

$\begin{array}{llllllllllll}\text { C } & 10 & 9 & 9 & 8 & 8 & 8 & 8 & 7 & 6 & 4 & 4\end{array}$

$\begin{array}{llllllllllll}\mathrm{D} & 7 & 7 & 7 & 6 & 5 & 5 & 5 & 5 & 3 & 2 & 1\end{array}$

- A - no residual cervical cancer + negative nodes

B - residual cervical cancer + negative nodes

- - C - no residual cervical cancer + involved nodes

- D - residual cervical cancer + involved nodes

Fig. 4. Disease-free survival (DFS) according to post-operative histopathology results

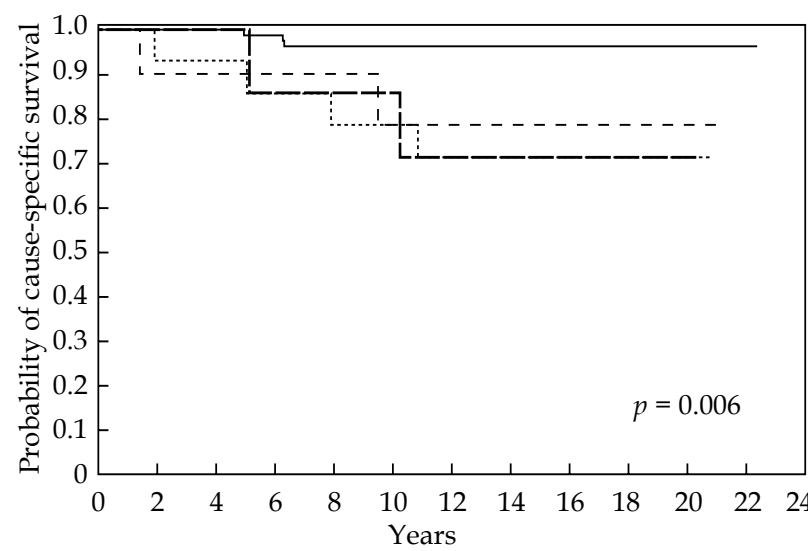

- A - no residual cervical cancer + negative nodes

- B - residual cervical cancer + negative nodes

- - C - no residual cervical cancer + involved nodes

- D D - residual cervical cancer + involved nodes

Fig. 5. Cause-specific survival (CSS) according to post-operative histopathology results

Society for Radiotherapy and Oncology [GEC-ESTRO] recommendations) delivered with a hybrid intracavitary and interstitial applicator (Nice Gynecologic Applicator), and showed pCR in $88.5 \%$ of cases [12], but with a rather

Table 4. Cox regression of DFS $(n=113)$

\begin{tabular}{llll} 
Response to pHDR-BT and lymph node status & HR & $95 \% \mathrm{Cl}$ & $p$-value \\
\hline No residual cervical cancer and negative lymph nodes & 1.0 & & \\
\hline No residual cervical cancer and involved lymph nodes & 5.99 & $1.00-35.85 \%$ & 0.050 \\
\hline Residual cervical cancer and negative lymph nodes & 9.07 & $2.03-40.58 \%$ & 0.004 \\
\hline Residual cervical cancer and involved lymph nodes & 8.18 & $1.37-48.96 \%$ & 0.021
\end{tabular}


Table 5. LDR, PDR, and HDR pre-operative brachytherapy in early operable cervical cancer

\begin{tabular}{|c|c|c|c|c|c|c|c|c|c|c|}
\hline $\begin{array}{l}\text { Authors, } \\
\text { year [Ref.] }\end{array}$ & $\begin{array}{l}\text { Dose } \\
\text { rate }\end{array}$ & $n$ & FIGO & $\begin{array}{l}\text { FU } \\
(\mathrm{m})\end{array}$ & $\begin{array}{c}\text { Complete } \\
\text { histological } \\
\text { response } \\
\end{array}$ & OS & DFS & $\begin{array}{l}\text { Grade } 3-4 \\
\text { toxicity }\end{array}$ & $\begin{array}{l}\text { Local } \\
\text { recurrence }\end{array}$ & $\begin{array}{l}\text { Adjuvant } \\
\text { treatment }\end{array}$ \\
\hline $\begin{array}{l}\text { Calais } \\
\text { et al., } 1989 \\
{[18]}\end{array}$ & LDR & 115 & $\begin{array}{l}\text { IB: } 70 \\
\text { IIA: } 45\end{array}$ & 72 & $\begin{array}{l}\text { IB: } 87.0 \% \\
\text { IIA: } 69.0 \%\end{array}$ & $\begin{array}{l}92.0 \% \\
\text { at } 5 \text { yrs. }\end{array}$ & N.A. & $\begin{array}{c}\text { GU: } 0.9 \% \\
\text { GI: } 1.7 \% \\
\text { Lymphatics: } 3.5 \%\end{array}$ & IB: $0.0 \%$ & RT: $16.5 \%$ \\
\hline $\begin{array}{l}\text { Gerbaulet } \\
\text { et al., } 1992 \\
{[19]}\end{array}$ & LDR & 441 & $\begin{array}{l}\text { IB: } 288 \\
\text { II: } 103\end{array}$ & N.A. & N.A. & $\begin{array}{l}87.0 \% \\
\text { at } 5 \text { yrs. }\end{array}$ & $\begin{array}{l}85.0 \% \\
\text { at } 5 \text { yrs. }\end{array}$ & $\begin{array}{l}\text { GU: } 7.3 \% \\
\text { GI: } 3.6 \%\end{array}$ & $5.0 \%$ & RT: $15.0 \%$ \\
\hline $\begin{array}{l}\text { Jedrus } \\
\text { et al., } 1997 \\
{[24]}\end{array}$ & HDR & 247 & $\begin{array}{l}\text { IB: } 171 \\
\text { IIA: } 76\end{array}$ & N.A. & $86.3 \%$ & N.A. & $86.2 \%$ & $1.2 \%$ & N.A. & RT: $25.1 \%$ \\
\hline $\begin{array}{l}\text { Resbeut } \\
\text { et al., } 2001 \\
{[21]}\end{array}$ & LDR & 192 & $\begin{array}{l}\text { IA2: } 28 \\
\text { IB1: } 144 \\
\text { IIA: } 20\end{array}$ & 61 & $71.3 \%$ & $\begin{array}{c}96.9 \% \\
\text { at } 5 \text { yrs. }\end{array}$ & $\begin{array}{c}91.2 \% \\
\text { at } 5 \text { yrs. }\end{array}$ & GU: $0.5 \%$ & $1.0 \%$ & RT-CT: 9.8\% \\
\hline $\begin{array}{l}\text { Beskow } \\
\text { et al., } 2002 \\
{[22]} \\
\end{array}$ & LDR & 121 & $\begin{array}{l}\text { IB: } 97 \\
\text { IIA: } 24\end{array}$ & 71 & $79.0 \%$ & $\begin{array}{l}\text { IB: } 87.0 \% \\
\text { IIA: } 75.0 \%\end{array}$ & N.A. & GI: $0.8 \%$ & N.A. & RT: $19.0 \%$ \\
\hline $\begin{array}{l}\text { Haie-Meder } \\
\text { et al., } 2009 \\
\text { [10] }\end{array}$ & PDR & 39 & $\begin{array}{l}\text { IB1: } 37 \\
\text { IIA: } 1 \\
\text { IIB: } 1\end{array}$ & 52.8 & $64.1 \%$ & $\begin{array}{l}94.0 \% \\
\text { at } 4 \text { yrs. }\end{array}$ & $\begin{array}{l}86.0 \% \\
\text { at } 4 \text { yrs. }\end{array}$ & $0.0 \%$ & $2.6 \%$ & RT-CT: $15.4 \%$ \\
\hline $\begin{array}{l}\text { Ngo et al., } \\
2011 \text { [3] }\end{array}$ & LDR & 257 & $\begin{array}{l}\text { IB1: } 231 \\
\text { IIA: } 17 \\
\text { IIB: } 9\end{array}$ & 122 & $56.0 \%$ & $\begin{array}{l}83.0 \% \\
\text { at } 5 \text { yrs. }\end{array}$ & $\begin{array}{l}80.9 \% \\
\text { at } 5 \text { yrs. }\end{array}$ & $2.7 \%$ & $13.2 \%$ & RT: $19.0 \%$ \\
\hline $\begin{array}{l}\text { Uzan } \\
\text { et al., } 2013 \\
{[4]}\end{array}$ & $\begin{array}{l}\text { LDR } \\
\text { PDR }\end{array}$ & 162 & IB1: 162 & 39 & $75.3 \%$ & $\begin{array}{l}95.0 \% \\
\text { at } 5 \text { yrs. }\end{array}$ & $\begin{array}{l}94.3 \% \\
\text { at } 5 \text { yrs. }\end{array}$ & $\begin{array}{c}\text { GU: } 3.7 \% \\
\text { GI: } 0.6 \% \\
\text { Vaginal: } 3.1 \% \\
\text { Lymphatics: } 4.3 \%\end{array}$ & $5.5 \%$ & RT-CT: $11.7 \%$ \\
\hline $\begin{array}{l}\text { Han- } \\
\text { noun-Levi } \\
\text { et al., } 2013 \\
{[12]}\end{array}$ & HDR & 32 & $\begin{array}{l}\text { IB1: } 30 \\
\text { IIA: } 2\end{array}$ & 24 & $88.5 \%$ & N.A. & N.A. & $0.0 \%$ & $0.0 \%$ & $0.0 \%$ \\
\hline $\begin{array}{l}\text { Vízkeleti } \\
\text { et al., } 2015 \\
\text { [25] }\end{array}$ & HDR & 70 & $\begin{array}{l}\text { IA2: } 2 \\
\text { IB1: } 39 \\
\text { IB2: } 15 \\
\text { IIA: } 11 \\
\text { IIB: } 3\end{array}$ & 29 & $25.7 \%$ & $\begin{array}{c}85.2 \% \\
\text { at } 5 \text { yrs. }\end{array}$ & N.A. & N.A. & $4.3 \%$ & $\begin{array}{c}\text { RT, RT-CT: } \\
64.3 \%\end{array}$ \\
\hline $\begin{array}{l}\text { Lacorre } \\
\text { et al., } 2016 \\
\text { [16] }\end{array}$ & LDR & 74 & $\begin{array}{l}\text { IA1: } 1 \\
\text { IA2: } 6 \\
\text { IB1: } 64 \\
\text { IIA: } 3\end{array}$ & N.A. & $47.3 \%$ & $92.3 \%$ & $92.3 \%$ & $\begin{array}{c}\text { GU: } 2.7 \% \\
\text { GI: } 1.3 \% \\
\text { Vaginal: } 0.0 \%\end{array}$ & $1.3 \%$ & $0.0 \%$ \\
\hline $\begin{array}{l}\text { Escande } \\
\text { et al., } 2016 \\
\text { [9] }\end{array}$ & PDR & 77 & $\begin{array}{l}\text { IB1: } 74 \\
\text { IIA1: } 3\end{array}$ & 46.8 & $70.1 \%$ & $\begin{array}{l}84.6 \% \\
\text { at } 5 \text { yrs. }\end{array}$ & $\begin{array}{l}84.4 \% \\
\text { at } 5 \text { yrs. }\end{array}$ & $\begin{array}{c}\text { GU: } 1.3 \% \\
\text { GI: } 1.3 \% \\
\text { Vaginal: } 5.2 \% \\
\end{array}$ & $1.3 \%$ & RT-CT: $15.6 \%$ \\
\hline $\begin{array}{l}\text { Escande } \\
\text { et al., } 2017 \\
\text { [17] }\end{array}$ & $\begin{array}{l}\text { LDR/ } \\
\text { PDR }\end{array}$ & 182 & $\begin{array}{l}\text { IB1: } 176 \\
\text { IIA1: } 6\end{array}$ & 64 & $69.8 \%$ & $\begin{array}{l}92.2 \% \\
\text { at } 5 \text { yrs. }\end{array}$ & $\begin{array}{l}91.0 \% \\
\text { at } 5 \text { yrs. }\end{array}$ & $0.0 \%$ & $1.6 \%$ & RT-CT: $14.3 \%$ \\
\hline $\begin{array}{l}\text { Cagetti } \\
\text { et al., } 2021 \\
{[15]}\end{array}$ & HDR & 70 & $\begin{array}{l}\text { IB1: } 13 \\
\text { IB2: } 53 \\
\text { IIA: } 4 \\
\text { (FIGO } \\
\text { 2018) }\end{array}$ & 37.4 & $62.9 \%$ & $\begin{array}{l}97.0 \% \\
\text { at } 3 \text { yrs. }\end{array}$ & $\begin{array}{l}88.0 \% \\
\text { at } 3 \text { yrs. }\end{array}$ & Vaginal: 7.1\% & $8.6 \%$ & $0.0 \%$ \\
\hline $\begin{array}{l}\text { Present } \\
\text { study }\end{array}$ & HDR & 113 & $\begin{array}{l}\text { IB1: } 12 \\
\text { IB2: } 42 \\
\text { IIA1: } 59\end{array}$ & 210 & $81.4 \%$ & $\begin{array}{c}97.3 \% \\
\text { at } 5 \mathrm{yrs} \text {. } \\
85.0 \% \\
\text { at } 10 \mathrm{yrs} \text {. }\end{array}$ & $\begin{array}{c}92.9 \% \\
\text { at } 5 \mathrm{yrs} \text {. } \\
90.2 \% \\
\text { at } 10 \mathrm{yrs} \text {. }\end{array}$ & $\begin{array}{l}\text { GU: } 1.8 \% \\
\text { GI: } 2.6 \%\end{array}$ & $4.4 \%$ & $\begin{array}{l}\text { RT-CT, CT, } \\
\text { RT: } 28.3 \%\end{array}$ \\
\hline
\end{tabular}

Based on Cagetti et al. [15]; GU - genitourinary; GI - gastrointestinal; RT - radiotherapy; CT - chemotherapy; RT-CT - radiochemotherapy; N.A. - not available 
short two-year median follow-up and within small group of 32 patients. On the other hand, one prospective, randomized study using pHDR-BT reported pCR in only $25.7 \%$ of patients [25]. Total and fractional doses are key factors affecting both efficacy and toxicity in pHDR-BT. No uniform standard $\mathrm{pBT}$ schedule has been adopted [28]. In a pHDR-BT study with a lowest pCR rates, two fractions of 8 Gy were given [25], and this may be linked to a lower response rate. In our study, a 5 Gy dose was specified to point $\mathrm{A}$, given twice a week to a total dose of $30 \mathrm{~Gy}$. Hannoun-Levi et al. administered $39 \mathrm{~Gy}$ in nine fractions over 5 days [12].

Lymph node status is a major prognostic factor and important issue in selection of appropriate therapy and treatment planning $[8,14,18]$. In IB stage patients, pelvic lymph node metastases are found in up to $17.0 \%$, and in IIA patients in $12-30.0 \%$ of cases [21, 29]. In our study, lymph nodes involvement was present post-operatively in $15.0 \%$ of patients and were more often seen in IIA1 patients. In a study by Ngo et al., which followed a similar group of patients over a similar period of time, lymph node involvement was observed in almost $18.0 \%$ of cases [3]. Resbeut et al. found that the presence of lymph node involvement on primary diagnosis was a risk factor for any recurrence [21]. Other data show that lymph node involvement is correlated with worse survival in all groups of patients [3, 4], which was confirmed by our results. In Cox analysis, lymph node involvement and FIGO IIA1 correlated with worse survival in all groups of patients. When we started treatment with pHDR-BT, neither MRI nor CT was routinely performed in our department [24] All patients had lymph nodes removed during hysterectomy after $\mathrm{pHDR}-\mathrm{BT}$. This group of patients needs careful lymph node evaluation before qualification for $\mathrm{pBT}$. Nowadays, they routinely undergo advanced imaging, such as MRI and positron emission tomography-computed tomography (PET-CT) or laparoscopic pelvic lymph node dissection $[12,29]$, which facilitates exclusion from pBT and identifies those who need more aggressive treatment. Hannoun-Levi et al. performed MRI and PET-CT, followed by laparoscopic pelvic lymph node dissection. Patients with lymph node involvement underwent radiochemotherapy, followed by brachytherapy [12]. Escande et al. used only pre-operative MRI, and only patients with no lymph node involvement on MRI were qualified for pBT [9]. Laparoscopic nodal staging before brachytherapy is a very valuable method for evaluating nodal status $[4,15]$, but in our experience, patients often do not agree to two-step surgical procedures.

Only one prospective randomized trial comparing primary surgery to $\mathrm{pBT}$, followed by surgery has been conducted [25]. However, other therapeutic strategies for early operable tumors show similar efficacy [30]. Radiotherapy and primary surgery in early, operable cervical cancer have similar survival rates, with a local relapse rate ranging from $13.0 \%$ to $18.0 \%[3,5,9,17,30]$.

Treatment failures occur more often among patients with tumor $\geq 2.0 \mathrm{~cm}$, with LVSI, involved lymph nodes, adenocarcinoma histology, positive post-operative margins, or involved parametria [9, 12, 15, 17]. However, even in the absence of these well-defined risk factors, failures may occur in approximately $10-20.0 \%$ of patients with early-stage cervical cancer, probably because of micro-metastases.

In our study, we observed $4.4 \%$ local recurrences, and our results are similar to those from other studies with pLDR-BT and pPDR-BT carried out over approximately the same period of time $[3,5,21]$ and with similar proportions of FIGO IIA1 patients. In recent years, studies have concentrated on a IB1 and IB2 group (FIGO 2018) as the most suitable for pBT $[5,13,16,17]$. In the present study, all failures were diagnosed in IIA1 patients, and for this reason, a decade ago, we started qualifying IIA1 patients for $\mathrm{pBT}$ only in highly selected cases, using much stricter criteria than before. New studies based on GEC-ESTRO recommendations, with limited numbers of patients with FIGO IIA1, show very low numbers of local failures. Escande et al. noted only 1.6\% local recurrences [17]. Similarly, Cagetti et al. observed only $1.4 \%$ local and pelvic recurrences [15]. Hannoun-Levi et al. did not observe any failures [12]. However, in cervical carcinoma, most local relapses occur less than 2 years after treatment [13]. In our study, the median time to pelvic recurrence and to distant metastases was 33 and 56 months, respectively. This confirms that extended follow-up is needed, even in early cervical cancer.

Some studies have shown that pBT may decrease the risk of positive surgical margins and reduce the frequency of parametrial spread $[4,15,21,25]$. In our study, there was no case of margin involvement. Cagetti et al. observed positive margins only in one case [15]. In a study by Vízkeleti et al., the rate of positive surgical margins was $1.5 \%$, and positive margin rates were significantly lower compared to control group that did not receive pHDR-BT [25]. Uzan et al. suggested that in patients properly qualified for $\mathrm{pBT}$, less radical surgery, i.e., simple extra-fascial hysterectomy, may be sufficient. They described radical hysterectomy using a laparoscopic approach after pBT for stage IB1 patients with excellent survival and morbidity, close to that reported in patients treated with up-front surgery, with parametrial spread of $0.6 \%$ [4]. Parametrial spread reported by other authors ranged from $0.5 \%$ to $4.3 \%[3,4,17]$, which is similar to the figure found in our study $(3.5 \%$, all in IIA1 patients).

Patients selected for $\mathrm{pBT}$ may omit post-operative EBRT, which is associated with higher toxicity [20, 25]. Today, however, when intensity-modulated radiation therapy (IMRT) is routinely used, toxicity is less frequent, although still detectable $[13,30]$. Toxicity is a significant factor for women with early cervical cancer due to longer survival. In the period of our study, we followed a protocol under which, patients with LVSI, residual cervical cancer after $\mathrm{pBT}$, involved lymph nodes, or parametrial involvement were qualified for adjuvant therapy. Late severe toxicity was more common among patients who received adjuvant EBRT. In the literature, the percentage of cases of late severe toxicity in $\mathrm{pBT}$ ranged from $5.0 \%$ to $15.0 \%[3,6,18]$, but nowadays, when image-guided brachytherapy is performed, the number of complications is lower [6, 7]. In a French prospective study with 
pPDR-BT, the authors demonstrated a $50.0 \%$ decrease of grade 2-4 toxicity after two years with 3D compared to $2 \mathrm{D}$ dosimetry in cervical cancer patients [11]. In our study, among patients treated with sole pHDR-BT, only one vesicovaginal fistula was observed.

A limitation of our study is the fact that it was a retrospective analysis. On the other hand, the long follow-up allows for long-term evaluation of effectiveness and late treatment toxicity. In the period of our analysis, treatment planning was based on X-ray, but in our opinion, our study is still useful in view of the low number of studies published using pHDR-BT.

\section{Conclusions}

Pre-operative HDR-BT in early cervical cancer is well-tolerated and effective in sterilizing tumor cells in the cervix. The growing number of publications in this area may help define an optimal therapeutic scheme, but randomized trials are required to determine the best candidates for this treatment modality.

In our opinion, cervical cancer patients with FIGO stage IIA1 are not good candidates for pHDR-BT, and could be given this treatment only after rigorous selection, including assessment with state-of-the-art imaging, due to higher probability of treatment failure.

\section{Acknowledgments}

We would like to pay our special respects to the late Dr. Brygida Białas, the former Head of the Brachytherapy Department in Maria Skłodowska-Curie National Research Institute of Oncology (Gliwice), who developed pHDR-BT in our center.

\section{Disclosure}

The authors report no conflict of interest.

\section{References}

1. Vu M, Yu J, Olutosin A et al. Cervical cancer worldwide. Curr Probl Cancer 2018; 42: 457-465.

2. Cohen PA, Jhingran A, Oaknin AA et al. Cervical cancer. Lancet 2019; 393: 169-182.

3. Ngo C, Alran S, Plancher C et al. Outcome in early cervical cancer following pre-operative low dose rate brachytherapy: A ten-year follow up of 257 patients treated at a single institution. Gynecol Oncol 2011; 123: 248-252.

4. Uzan C, Merlot B, Gouy S et al. Laparoscopic radical hysterectomy after preoperative brachytherapy for stage IB1 cervical cancer: feasibility, results, and surgical implications in a large bicentric study of 162 consecutive cases. Ann Surg Oncol 2013; 20: 872-880.

5. Atlan D, Touboul E, Deniaud-Alexandre E et al. Operable Stages IB and II cervical carcinomas: a retrospective study comparing preoperative utero-vaginal brachytherapy and postoperative radiotherapy. Int J Radiat Oncol Biol Phys 2002; 54: 780-793.

6. Cibula D, Pötter R, Planchamp F et al. The European Society of Gynaecological Oncology/European Society for Radiotherapy and Oncology/European Society of Pathology guidelines for the management of patients with cervical cancer. Radiother Oncol 2018; 127: 404-416.
7. Huertas A, Oldrini S, Nesseles JP et al. FIGO stage IB1 cervical carcinoma: Place and principles of brachytherapy. Cancer Radiother 2017; 21: 155-163.

8. Haie-Meder C, Potter R, van Limbergen E et al. Recommendations from Gynaecological (GYN) GEC-ESTRO Working Group (I): concepts and terms in 3D image based 3D treatment planning in cervix cancer brachytherapy with emphasis on MRI assessment of GTV and CTV. Radiother Oncol 2005; 74: 235-245.

9. Escande A, Mazeron R, Gouy S et al. Preoperative image-guided brachytherapy in early cervical cancers. Radiother Oncol 2016; 120: 455-459.

10. Haie-Meder C, Chargari C, Rey A et al. DVH parameters and outcome for patients with early-stage cervical cancer treated with preoperative MRI-based low dose rate brachytherapy followed by surgery. Radiother Oncol 2009; 93: 316-321.

11. Magné N, Casanova Mancy N, Chajon E et al. Patterns of care and outcome in elderly cervical cancer patients: A special focus on brachytherapy. Radiother Oncol 2009; 91: 197-201.

12. Hannoun-Levi JM, Chand-Fouche ME, Gautier M et al. Interstitial preoperative high-dose-rate brachytherapy for early stage cervical cancer: Dose volume histogram parameters, pathologic response and early clinical outcome. Brachytherapy 2013; 12: 148-155.

13. Charra-Brunaud C, Harter V, Delannes M et al. Impact of 3D image-based PDR brachytherapy on outcome of patients treated for cervix carcinoma in France: Results of the French STIC prospective study. Radiother Oncol 2012; 10: 305-313.

14. Bataille B, le Tinier F, Escande A et al. Intracavitary preoperative brachytherapy followed by Whertheim-type hysterectomy in localized cervical cancer: clinical data and toxicity results from a single institution experience. Int J Radiat Oncol Biol Phys 2019; 105 (1) suppl: 319-320.

15. Cagetti LV, Gonzague-Casabianca L, Zemmour C et al. The impact of modern preoperative high-dose-rate brachytherapy in early-stage cervical cancer. Gynecol Oncol 2021; 161: 166-172.

16. Lacorre A, Merlot B, Garabedian C et al. Early stage cervical cancer: Brachytherapy followed by type a hysterectomy versus type $B$ radical hysterectomy alone, a retrospective evaluation. EJSO 2016; 42: 376-382.

17. Escande A, Gouy S, Mazeron R et al. Outcome of early stage cervical cancer patients treated according to a radiosurgical approach: Clinical results and prognostic factors. Gynecol Oncol 2017; 144: 541-546.

18. Calais G, le Floch O, Chuvet B et al. Carcinoma of the uterine cervix stage IB and early stage II. Prognostic value of the histological tumor regression after initial brachytherapy. Int J Radiat Oncol Biol Phys 1989; 18: 1231-1235.

19. Gerbaulet AL, Hunkler IH, Haie $\mathrm{C}$ et al. Combined radiotherapy and surgery: local control and complications in early carcinoma of the uterine cervix - the Villejuif experience, 1975-1984. Radiother Oncol 1992; 23: 66-73.

20. Landoni F, Maneo A, Colombo A et al. Randomised study of radical surgery versus radiotherapy for stage Ib-IIa cervical cancer. Lancet 1997; 350: 535-540.

21. Resbeut MR, Alzieu C, Gonzague-Casabianca L et al. Combined brachytherapy and surgery for early carcinoma of the uterine cervix: analysis of extent of surgery on outcome MR. Int J Radiat Oncol Biol Phys 2001; 50: 873-881.

22. Beskow C, Agren-Cronqvist AK, Granath F et al. Pathologic complete remission after preoperative intracavitary radiotherapy of cervical cancer stage $\mathrm{Ib}$ and IIa is a strong prognostic factor for long-term survival: analysis of the Radiumhemmet data 1989-1991. Int J Gynecol Cancer 2002; 12: 158-170.

23. Grigsby PW, Perez CA, Chao KS et al. Lack of effect of tumor size on the prognosis of carcinoma of the uterine cervix Stage 
IB and IIA treated with preoperative irradiation and surgery. Int J Radiat Oncol Biol Phys 1999; 45: 645-651.

24. Jedrus S, Rzempołuch J, Owczarek S et al. Efficiency of combined treatment for cervical carcinoma with special regard to preoperative HDR brachytherapy. Neoplasms 1997; 47: 527-537.

25. Vízkeleti J, Vereczkey I, Fröhlich G et al. Pathologic complete remission after preoperative high-dose-rate brachytherapy inpatients with operable cervical cancer: preliminary results of a prospective randomized multicentre study. Pathol Oncol Res 2015; 21: 247-256.

26. Grigsby PW, Massad LS, Mutch DG et al. FIGO 2018 staging criteria for cervical cancer: impact on stage migration and survival. Gynecol Oncol 2020; 157: 639-643.

27. Common Terminology Criteria for Adverse Events (CTCAE) Version 5.0 published: November 27, 2017 U.S. Department Of Health And Human Services. Available online: https:// ctep.cancer.gov/protocoldevelopment/electronic_applications/docs/ctcae_v5_quick_reference_5x7.pdf.

28. Nag S, Erickson B, Thomadsen B et al. The American Brachytherapy Society recommendations for high-dose-rate brachytherapy for carcinoma of the cervix. Int J Radiat Oncol Biol Phys 2000; 48: 201-211.

29. Chung HH, Kang SB, Cho JY et al. Can preoperative MRI accurately evaluate nodal and parametrial invasion in early stage cervical cancer? Jpn J Clin Oncol 2007; 37: 370-375.

30. Toita T, Kato S, Niibe $Y$ et al. Prospective multi-institutional study of definitive radiotherapy with high-dose-rate intracavitary brachytherapy in patients with non bulky $(<4-\mathrm{cm})$ stage I and II uterine cervical cancer (JAROG0401/ JROSG04-2). Int J Radiat Oncol Biol Phys 2012; 82: 49-56. 